\title{
Rastreo de cáncer de cuello uterino mediante detección de ADN del virus del papiloma humano y/o Papanicolau
}

\author{
Cervical cancer screening by DNA-human papiloma virus and Papanicolau smear
}

Mayrand M y col. N Engl J Med.2007; 357(16):1579-88

\section{Objetivo}

Comparar dos métodos de rastreo de cáncer de cuello uterino (CCU): Papanicolau y prueba de detección del acido desoxirrebonucleico del virus del papiloma humano (ADN-HPV).

\section{Diseño}

Ensayo clínico controlado y aleatorizado.

\section{Lugar}

30 clínicas de Montreal y Saint John, Canadá.

\section{Pacientes}

Se incluyeron 10.154 mujeres de 30 a 69 años de edad que se habían presentado para rastreo rutinario de CCU durante dos años y cinco meses.

\section{Intervención}

Fueron aleatorizadas a dos grupos denominados "grupo inicio con Papanicolau" y "grupo inicio con ADN-HPV". A los dos grupos se les realizaron ambas pruebas, variando el orden según el grupo asignado. A las que tuvieron un resultado positivo en alguna de las pruebas iniciales (ASCUS, SIL de bajo o alto grado, carcinoma y/o adenocarcinoma en el Papanicolau; o más de $1 \mathrm{pg} / \mathrm{mL}$ de ADN-HPV) se les realizó una colposcopía y una biopsia. A quienes tuvieron en la biopsia CIN2 ó lesiones de mayor gravedad se les realizó un LEEP y se confirmó el diagnostico con anatomía patológica. Para estimar la sensibilidad de ambas pruebas y ante la imposibilidad económica y operativa de realizar una biopsia a todas las mujeres se seleccionó en forma aleato- ria a un subgrupo estratificado* de un $10 \%$ de las mujeres en St. John's y $20 \%$ en Montreal con pruebas de rastreo negativas (PAP y ADN-HPV) para realizar colposcopía y biopsia.

\section{Medición de resultados principales}

Sensibilidad, especificidad, valor predictivo positivo (VPP) y negativo (VPN) de ambas pruebas biopsia CIN2 ó lesiones de mayor gravedad. Ver tabla 1

Tabla 1: características operativas del Papanicolau y el ADN-HPV.

\begin{tabular}{c|c|c|c|c|c|c}
$\begin{array}{c}\text { Prueba } \\
\text { de } \\
\text { rastreo }\end{array}$ & $\begin{array}{c}\text { Definición } \\
\text { de } \\
\text { prueba positiva }\end{array}$ & Sensibilidad & Especificidad & \multicolumn{2}{|c|}{$\begin{array}{c}\text { Valor } \\
\text { predictivo }\end{array}$} & $\begin{array}{c}\text { Derivación } \\
\text { a }\end{array}$ \\
\cline { 5 - 6 } Papanicolaun & ASCUS o peor & $56,4 \%$ & $97,3 \%$ & $8,5 \%$ & $99,8 \%$ & $2,9 \%$ \\
\hline ADN-HPV & Más de 1pg/mL & $97,4 \%$ & $94,3 \%$ & $7 \%$ & $100 \%$ & $6,1 \%$ \\
\hline Ambas & En forma secuencial & $53,8 \%$ & 98,7 a & 14,9 a & $99,8 \%$ & 1,1 a \\
pruebas & \multirow{2}{*}{ Simultáneamente } & & $99,1 \%$ & $21,4 \%$ & & $1,6 \%$ \\
\cline { 5 - 6 } & & $100,0 \%$ & $92,5 \%$ & $5,5 \%$ & $100 \%$ & $7,9 \%$ \\
\hline
\end{tabular}

aRealizando la segunda prueba solamente a las mujeres que habían tenido resultado positivo en la primera.

\section{Conclusiones}

La prueba de ADN-HPV tiene mayor sensibilidad que la de PAP y menor especificidad. EI PAP tiene mas alto VPP que el HPV y ambos tienen muy alto VPN (99,8 y 100\%). La sensibilidad de la combinación de ambas pruebas es de $100 \%$, la especificidad de $92,5 \%$, el VPP de $5,5 \%$ y el VPN de $100 \%$.

Palabras claves: rastreo de cáncer de cervix, papanicolau, ADN anti HPV. Key words: cervical cancer screening, Papanicolau smear, DNA anti HPV.

Fuentes de financiamiento: Canadian Institutes of Health Research y Merck Frosst Canada.

\section{Comentario}

Si bien los resultados muestran valores aceptables de sensibilidad y especificidad de la prueba de ADN-HPV, su aplicación en nuestro país se ve afectada por varios motivos: 1) su alto costo la vuelve por el momento inaccesible; 2) nuestra población tiene alta prevalencia de infección por HPV y la mayoría de las pacientes presenta una regresión espontánea; 3) No sorprende la mayor sensibilidad de la prueba ADN-HPV ya que el presente estudio la comparó con una sola toma aislada de PAP. La estrategia habitual de rastreo con Papanicolau es la realización periódica, lo que aumenta la sensibilidad de dicha estrategia; 4) la inclusión del la prueba de ADN-HPV implicaría aumentar el numero de procedimientos invasivos (colposcopias) y agresivos (biopsias) sin un mayor rédito en la detección de cáncer si se compara esta estrategia con la de realización de Papanicolau anual. Sin embargo, en las mujeres de mayor riesgo en quienes el rastreo no se realiza con la periodicidad recomendada, un test más sensible como el de HPV podría resultar importante, y el beneficio potencial podría compensar los mayores costos.

Por último, la presencia de ADN-HPV no implica que este se halle dentro de una célula en replicación.
La vacuna de HPV puede abrir una nueva era en la prevención del CCU, específicamente aquellos relacionados con HPV tipo 16 y 18. No obstante, dados los costos, es poco probable que la población de mayor riesgo sea la que reciba masivamente la vacuna. Debido a esta situación, es en las estrategias de rastreo periódico donde debemos poner mayor énfasis.

Considerando el bajo VPP de las pruebas, y si en un futuro disminuyera la prevalencia de HPV, será necesario mejorar sustancialmente la especificidad de las pruebas para su detección y de esta manera evitar una epidemia de resultados falsos positivos.

\section{Conclusión de la comentadora}

Teniendo en cuenta que en Argentina el CCU es responsable del $10 \%$ de la mortalidad femenina por cáncer y se ubica en el sexto lugar como causa de muerte , antes de la incorporación de nuevas tecnologías no debemos perder el principal foco de nuestra estrategia de rastreo del CCU: la realización masiva del Papanicolau con la periodicidad adecuada para cada subpoblación de riesgo. Esto garantizará una sensibilidad adecuada de una estrategia que ha superado la prueba de la historia durante el siglo XX.

Yamila De Vas [ Servicio de Medicina Familiar y Comunitaria del Hospital Italiano. yamila.devas@hospitalitaliano.org.ar ]

Ver glosario*

De Vas Y. Rastreo de cáncer de cuello uterino mediante detección de ADN del virus del papiloma humano y/o Papanicolau. Evid. actual. práct. ambul; 11(3): 140, May-Jun.2008. Comentado de: Mayrand M, Duarte-Franco D ,Rodriguez I y col. Human Papillomavirus DNA versus Papanicolaou Screening Tests for Cervical Cancer. N Engl J Med. 2007; 357(16):1579-88. PMID: 17942871.

Disponible en URL: http://content.nejm.org/cgi/reprint/357/16/1579.pdf (último acceso 14/06/08).

Referencias

1. Giraudo N, Discacciati V ,Bakalar K, Basualdo N y Dreyer C. Barreras para el rastreo de cáncer de cuello uterino en la Ciudad de Buenos Aires. Archivos de Medicina Familiar y General.Volumen 3 Número 2 - 2006. pp 7-21. Disponible en URL: http://www.famfyg.org.ar/revista/revista_famfyg/volumen3_n2/investigacion_01.pdf (último acceso 14/06/08). 